\title{
DELINEAMENTO DOS ACIDENTES DE TRABALHO EM INSTITUIÇÕES DE SAÚDE DE UMA MICRORREGIÃO DE MINAS GERAIS
}

\author{
Jaqueline da Silva Izidoro', Helena Hemiko Iwamoto², Fernanda Carolina Camargo ${ }^{3}$
}

\begin{abstract}
RESUMO: Na perspectiva de delinear a ocorrência de acidentes de trabalho de uma microrregião de Minas Gerais, realizou-se este estudo de caráter descritivo e retrospectivo. Utilizou-se como fonte de dados a notificação compulsória encaminhada para a Vigilância Epidemiológica. Os resultados evidenciaram o predomínio de acidentes de trabalho entre os trabalhadores da área de enfermagem $(43,1 \%)$, com menos de 30 anos $(39,8 \%)$, e com ensino médio completo (38,7\%), sendo $68,8 \%$ resultantes de procedimentos de menor complexidade como administrar medicamentos e descarte de material. $\mathrm{O}$ alto índice de acidentes de trabalho entre os trabalhadores de enfermagem retrata uma situação contraditória entre a obrigatoriedade da oferta de uma assistência de qualidade e a utilização de mecanismos de autoproteção.
\end{abstract}

PALAVRAS-CHAVE: Acidentes de trabalho; Vigilância epidemiológica; Enfermagem; Estudos epidemiológicos.

\section{DESIGN OF WORK ACCIDENTS IN HEALTH INSTITUTIONS IN MINAS GERAIS}

ABSTRACT: In order to delineate the accidents' occurrence in a micro-region of Minas Gerais, this descriptive and retrospective study was developed. The compulsory notification sent to the Epidemiological Surveillance was used as a data source. Results showed the prevalence of accidents among workers in nursing (43.1\%), with less than 30 years (39.8\%), and completed high school educational level (38.7\%), and 68, $8 \%$ of them was due to less complex procedures such as administering medications and materials disposal. The high rate of accidents among nursing workers portrays a contradictory situation between the mandatory provision of quality care and use of self-protection mechanisms.

KEYWORDS: Occupational accidents; epidemiological surveillance; Nursing; Epidemiological studies.

\section{DELINEAMIENTO DE LOS ACCIDENTES DE TRABAJO EN INSTITUIÇÕES DE SALUD DE UNA MICRORREGIÃO DE MINAS GERAIS}

RESUMEN: En la perspectiva de delinear la ocurrencia de accidentes de trabajo de una microrregión de Minas Gerais, fue realizado este estudio de carácter descriptivo y retrospectivo. Fue utilizada como fuente de datos la notificación compulsoria encaminada para la Vigilancia Epidemiológica. Los resultados evidenciaron el predominio de accidentes de trabajo entre los trabajadores del área de enfermería (43,1\%), con menos de 30 años $(39,8 \%)$, y con enseñanza media completa (38,7\%), siendo $68,8 \%$ resultantes de procedimientos de menor complejidad, como administrar medicinas y descarte de material. El alto índice de accidentes de trabajo entre los trabajadores de enfermería retrata una situación contradictoria entre la obligatoriedad de la oferta de una asistencia de cualidad y la utilización de mecanismos de autoprotección.

PALABRAS CLAVE: Accidentes de trabajo; Vigilancia epidemiológica; Enfermería; Estudios epidemiológicos.

'Enfermeira do Programa de Saúde da Família da Secretaria Municipal de Saúde de Uberaba-MG.

${ }^{2}$ Enfermeira. Doutora em Enfermagem. Professor Adjunto do Curso de Graduação em Enfermagem da Universidade Federal do Triângulo Mineiro-UFTM.

${ }^{3}$ Enfermeira. Especialista em Saúde da Família. Mestranda do Programa de Pós-Graduação em Atenção à Saúde da UFTM. Diretora do Departamento de Atenção Básica da Secretaria Municipal de Saúde de Uberaba-MG.

Autor correspondente:

Jaqueline da Silva Izidoro

Secretaria Municipal de Saúde de Uberaba

Rua José Teófilo Rodrigues, 32 - 38180-000 - Araxá-MG, Brasil

Recebido: 05/03/10

E-mail: jaquesing@yahoo.com.br

Aprovado: 05/06/10 


\section{INTRODUÇÃO}

Os acidentes de trabalho, de um modo geral, ocorrem a partir da ruptura da relação entre saúde e trabalho, de maneira abrupta ou insidiosa, com repercussões pessoais e sociais de expressiva monta ${ }^{(1)}$. Ressalta-se que os acidentes de trabalho estão, em grande parte, relacionados com a atividade laboral, as condições do local de trabalho e ao próprio trabalhador, segundo seu contexto sociopolítico.

Os números da Organização Internacional do Trabalho indicam que até $10 \%$ do Produto Interno Bruto dos países em desenvolvimento são gastos com problemas decorrentes de doenças e agravos ocupacionais. No Brasil, dos 376.240 agravos ocupacionais registrados no ano de 2000, 81\% resultaram em incapacidade temporária, $4 \%$ em incapacidade permanente, e $1 \%$ em óbitos ${ }^{(2)}$. Por estas razões, qualquer que seja a natureza dos acidentes de trabalho, deve ser observada sua potencialidade de afetar econômica e socialmente a realidade de um país, dadas as mortes prematuras e os anos potenciais de vida perdidos. É preciso considerar, também, a ocorrência de doenças ocupacionais ${ }^{(1,3-4)}$.

No Brasil, a notificação compulsória é o principal instrumento para o conhecimento de acidentes e doenças relacionadas ao trabalho, explicitando as causas pelas quais os trabalhadores adoecem ou mor$\mathrm{rem}^{(5)}$. Nesta perspectiva, a notificação compulsória da ocorrência de acidentes de trabalho permite reconhecer a gravidade destes acidentes e é uma ferramenta ímpar no delineamento de estratégias de prevenção e controle de agravos à saúde do trabalhador ${ }^{(4,6-7)}$.

Com relação aos trabalhadores de saúde, nos últimos anos, estes vêm ganhando destaque nas questões relacionadas à exposição ocupacional. Nos estabelecimentos de assistência à saúde, diversas são as ocasiões em que os trabalhadores enfrentam situações de risco em seu cotidiano, sendo levados a desconsiderar a sua importância e pouco modificando a prática para impedir os acidentes. Vale destacar que os trabalhadores de saúde estão expostos a diversos riscos ocupacionais causados por fatores químicos, físicos, mecânicos, biológicos, ergonômicos e psicossociais ${ }^{(6-7)}$.

Assim, ao considerar a notificação compulsória como meio para caracterizar a ocorrência e o tipo de acidente, conhecer os dados sociodemográficos, epidemiológicos e clínicos dos trabalhadores e, ainda, por entender que cada uma dessas dimensões integram uma cadeia de fatos a serem considerados para a construção de medidas que impliquem melhores condições de trabalho e controle das doenças ocupacionais ${ }^{(7)}$, este estudo tem como objetivo delinear a ocorrência de acidentes de trabalho entre os trabalhadores da saúde de uma Microrregião de Minas Gerais.

\section{MATERIAIS E MÉTODOS}

Trata-se de um estudo descritivo e retrospectivo orientado pelo referencial teórico da epidemiologia clássica. A população foi constituída por casos de acidentes de trabalhos em instituições de saúde, públicas e privadas, da Microrregião de Araxá, situada no Estado de Minas Gerais. As informações foram obtidas das fichas de Notificação Compulsória de Acidentes de Trabalho. O período estudado foi de $1^{\circ}$ de maio de 2007 a 31 de maio de 2009.

As variáveis estudadas foram aquelas que integravam os campos da ficha de notificação compulsória de acidentes de trabalho. Para fins de análise, selecionaram-se as variáveis sociodemográficas (idade, sexo, ocupação e escolaridade) e variáveis de exposição ocupacional (tipo de acidente, formas de exposição/circunstância e local de ocorrência).

$\mathrm{Na}$ coleta de dados, utilizou-se os dados disponibilizados pelo Departamento de Vigilância Epidemiológica responsável pelos Municípios de Araxá, Campos Altos, Ibiá, Perdizes, Pratinha, Pedrinópolis, Tapira e Santa Juliana. Todos os dados coletados foram armazenados em um banco de dados por meio de planilhas eletrônicas do programa Microsoft Excel e analisados a partir de frequências absolutas e relativas. Para análise estatística utilizou-se o programa Epi-Info versão 6.04 .

Por se tratar de um estudo com utilização de dados secundários e disponibilizados pelo setor público, isenta-se a obtenção de parecer do Comitê de Ética e Pesquisa com seres humanos.

\section{RESULTADOS E DISCUSSÃO}

Na Microrregião de Araxá foram notificados, em média, quatro acidentes de trabalho ao mês, totalizado a ocorrência de 93 acidentes durante o período dos dois anos em que decorreu o estudo. Uma das características observadas foi o elevado número de acidentes com trabalhadores do sexo feminino, 66 $(66,7 \%)$, o que significa que a cada três acidentes de trabalho, dois ocorreram com mulheres.

Estes dados indicam provavelmente que a grande força de trabalho na área de saúde está cons- 
tituída por mulheres, principalmente quando se trata de equipe de enfermagem. Estudo realizado em um Hospital Universitário de Brasília destacou que, dos 70 casos de acidentes de trabalho, houve predomínio $(78,6 \%)$ de ocorrência em mulheres ${ }^{(8)}$. Porém, estudo realizado na Bahia demonstrou que os casos mais graves ocorreram, em sua maioria, no sexo masculino ${ }^{(9)}$.

Em termos de notificação, qualquer que seja a modalidade de vínculo empregatício, todos os casos de acidentes de trabalho devem ser notificados ao setor responsável. Se o trabalhador pertencer ao regime celetista, no qual a relação entre o trabalhador e o empregador é regida pela Consolidação das Leis do Trabalho, a notificação deve ser feita através da Comunicação do Acidente de Trabalho, num período máximo de 24 horas. Se o trabalhador fizer parte do Regime Jurídico Único, ele tem um prazo de até dez dias após a ocorrência do acidente para fazer a notificação.

Em relação às categorias profissionais da Microrregião de Araxá, constatou-se que a maioria das notificações de acidentes de trabalho ocorreu com os trabalhadores que integram a equipe de enfermagem (Tabela 1). Esta categoria profissional participou em $43 \%$ das notificações, sendo $21,5 \%$ de técnicos em enfermagem; $16,1 \%$ de auxiliares de enfermagem; e $5,4 \%$ de enfermeiros. Outro dado que nos chamou atenção foi a ocorrência de acidentes de trabalho entre os profissionais de nível superior, como médico $(8,6 \%)$, cirurgião-dentista $(5,4 \%)$ e enfermeiro $(5,4 \%)$, totalizando $19,4 \%$ das notificações, visto que as demais categorias profissionais totalizaram $9,6 \%$.

Tabela 1 - Distribuição da notificação de acidentes de trabalho em instituições de saúde da Microrregião de AraxáMG, segundo função ou categoria profissional. Araxá, 2010.

\begin{tabular}{lcc}
\hline Função/Categoria Profissional & N. & $\mathbf{\%}$ \\
\hline Técnico em Enfermagem & 20 & 21,5 \\
Auxiliar de Enfermagem & 15 & 16,1 \\
Estudante & 11 & 11,9 \\
Médico & 8 & 8,6 \\
Enfermeiro & 5 & 5,4 \\
Cirurgião dentista & 5 & 5,4 \\
Motorista & 8 & 8,6 \\
Auxiliar de serviços gerais & 8 & 8,6 \\
Auxiliar de lavanderia e consultório dentário & 3 & 3,2 \\
Auxiliar de limpeza e esterilização de material & 1 & 1,1 \\
de laboratório & & \\
Outras categorias profissionais & 9 & 9,6 \\
Total & 93 & 100 \\
\hline
\end{tabular}

Fonte: Vigilância Epidemiológica da Secretaria Municipal de Saúde de Araxá-MG.
Estudo realizado em Brasília no período de 1998 a 2002 constatou que $27,8 \%$ dos acidentes de trabalho ocorreram com os profissionais de enfermagem (enfermeiro, técnico e auxiliares de enfermagem), e todas as demais categorias profissionais (médicos, dentistas, farmacêuticos, auxiliar de nutrição, pessoal de manutenção e limpeza e técnico de laboratório) perfaziam o percentual restante ${ }^{(10)}$. Da mesma forma, outros estudos realizados em diferentes regiões do país detectaram maior predisposição dos profissionais de enfermagem em sofrer acidentes de trabalho ${ }^{(8,10)}$.

Nesta perspectiva, a prevalência do alto índice de acidentes de trabalho entre os profissionais de enfermagem pode ser resultante da complexidade do processo de trabalho que envolve esta categoria profissional. Além disso, ela é responsável por diversos procedimentos que envolvem o "cuidar", que vão desde os mais simples até os de maior complexidade, e nas 24 horas do dia ${ }^{(10)}$.

Outros fatores como sobrecarga de trabalho, fatalidade, negligência e precariedade das condições de trabalho podem contribuir para o aumento das estatísticas de acidentes de trabalho. Somam-se a estas questões, também, a baixa remuneração praticada pelo mercado de trabalho de saúde que, fatalmente, leva os profissionais de saúde a cumprir uma jornada de trabalho acrescida com outros empregos, como forma de sobrevivência. Todas estas questões contribuem para a redução da atenção ao trabalho, levando-o a um desequilíbrio físico e emocional e tornando os profissionais de enfermagem os mais vulneráveis à ocorrência de acidentes no trabalho ${ }^{(8,10)}$.

Em especial, os trabalhadores de enfermagem estão expostos a riscos ambientais no trabalho, existentes nos espaços de trabalho, que incluem os agentes físicos, químicos e biológicos, capazes de causar danos à saúde do trabalhador em função de sua natureza, concentração/intensidade e tempo de exposição. O risco biológico advém da exposição a vírus, bactérias, protozoários, fungos, parasitas e bacilos; o risco físico das radiações ionizantes e não-ionizantes, ruídos, vibrações, frio, calor, pressões anormais e umidade; o risco químico, das substâncias, compostos ou produtos químicos, gases, vapores, neblinas, névoas, fumos e poeiras ${ }^{(11)}$.

Alguns estudos destacam que os profissionais de enfermagem, em particular os técnicos e auxiliares, estão mais expostos a fluidos corporais potencialmente infectantes, por serem responsáveis pelas tarefas de higienização, da administração de medicamentos, do 
manuseio e preparo de instrumentos cirúrgicos, do manuseio de excreções e fômites contaminados, além do ritmo exigido para o cumprimento das tarefas em tempo hábil ${ }^{(12-14)}$.

Quanto às causas de acidentes de trabalho na Microrregião de Araxá, 63,4\% das notificações estavam relacionadas com procedimentos de rotina como administração de medicamentos $(22,6 \%)$, cuidado direto ao paciente $(21,7 \%)$ e lavagem e descarte de material, com 19,3\% (Tabela 2).

Tabela 2 - Distribuição da notificação de acidentes de trabalho em instituições de saúde da Microrregião de Araxá-MG, segundo as causas. Araxá, 2010.

\begin{tabular}{lcc}
\hline Causas de acidente de trabalho & N. & \% \\
\hline Administração de medicamentos & 21 & 22,6 \\
Procedimentos (cuidado direto aos pacientes) & 20 & 21,7 \\
Lavagem e descarte inadequado de material & 18 & 19,3 \\
Acidente de trânsito & 13 & 14,0 \\
Lavanderia & 5 & 5,4 \\
Choque elétrico & 1 & 1,1 \\
Intoxicação & 1 & 1,1 \\
Soterramento & 1 & 1,1 \\
Outros & 13 & 14,0 \\
Total & 93 & 100 \\
\hline
\end{tabular}

Fonte: Vigilância Epidemiológica da Secretaria Municipal de Saúde de Araxá-MG.

Em estudo realizado em um hospital universitário da Região Sul do Brasil, com profissionais e estudantes de Enfermagem, foi observado que o principal objeto causador de acidentes citado pelos profissionais foi a agulha, fato possivelmente relacionado à não-utilização de Equipamentos de Proteção Individual (EPI) e Precauções-Padrão. O estudo faz referência a outros autores, no que diz respeito ao descarte inadequado de materiais perfurocortantes como uma das principais causas para o acidente, representando um importante risco para todos os trabalhadores da estrutura hospitalar ${ }^{(15)}$.

$\mathrm{Na}$ Microrregião de Araxá, os acidentes de trânsito totalizaram (14\%). Vale ressaltar a semelhança deste percentual com o Anuário Estatístico do Instituto Nacional de Seguridade Social de 2005, que indica a ocorrência de $13,7 \%$ de acidentes de trânsito no território nacional e 12,4\% em Minas Gerais. Entretanto, há que se destacar, ainda, outros estudos, como o da Bahia, que detectaram maior nível de gravidade em acidentes de trajeto, envolvendo atropelamentos ou colisões. Destes acidentes, as lesões mais graves foram os traumatismos de tórax e politraumatismos da região do quadril ou membros inferiores ${ }^{(9)}$.
Com relação à faixa etária, 39,8\% dos trabalhadores que sofreram acidentes de trabalho na Microrregião de Araxá, tinham menos de 30 anos e $60,2 \%$ de 30 a 50 anos (Tabela 3). Estes dados são extremamente preocupantes, uma vez que os elevados índices de acidentes de trabalho, tanto em profissionais com menos de 30 anos quanto acima desta faixa etária, podem ter uma correlação com a formação acadêmica, falta de qualificação profissional, sobrecarga de trabalho, falta de estrutura física e outras. Ao considerar-se que, teoricamente, os acidentes de trabalho são eventos passíveis de prevenção, estes índices podem estar comprometendo não somente a qualidade da assistência a ser prestada, mas também a imagem do profissional frente à sociedade.

Tabela 3 - Distribuição da notificação de acidentes de trabalho em instituições de saúde da Microrregião de Araxá-MG, segundo a faixa etária dos trabalhadores. Araxá, 2010.

\begin{tabular}{lcc}
\hline Faixa etária & N. & \% \\
\hline Menos de 20 anos & 5 & 5,4 \\
21 a 30 anos & 32 & 34,4 \\
31 a 40 anos & 24 & 25,8 \\
41 a 50 anos & 23 & 24,7 \\
Mais de 50 anos & 9 & 9,7 \\
Total & 93 & 100 \\
\hline
\end{tabular}

Fonte: Vigilância Epidemiológica da Secretaria Municipal de Saúde de Araxá-MG.

O estudo, realizado em 2007, identificou um elevado percentual de acidentes de trabalho em profissionais de 20 a 30 anos $(46,1 \%)$, e outros estudos constataram maior frequência de acidentes em profissionais acima dos 30 anos de idade, já com relativa experiência profissional, trabalhando na instituição de 6 a 10 anos, ou mais ${ }^{(4,8,10)}$.

Observou-se ainda, que entre os acidentados de trabalho da Microrregião de Araxá, o maior percentual correspondia àqueles profissionais que possuíam ensino médio completo $(38,7 \%)$ e ensino superior completo $(20,4 \%)$ (Tabela 4). Ao levar em consideração os acidentes de trabalho com profissionais de ensino médio completo, leva-se em conta que neste grupo inserem-se os técnicos e auxiliares de enfermagem, que pelas atividades que exercem, estão mais expostos aos riscos biológicos, incluindo-se aqueles com material perfurocortante. Assim, é preciso resgatar as resoluções que valorizem ou tornem obrigatório o uso de equipamentos de proteção individual (EPI). Já o elevado percentual de acidentes de traba- 
lho entre os trabalhadores com ensino superior completo $(20,4 \%)$ na Microrregião de Araxá, também pode estar atrelada ao não-uso do EPI para a realização de procedimentos. Entretanto, não podemos negar que há outros fatores que contribuem para o aumento dos acidentes de trabalho, tais como a falta de infraestrutura, a sobrecarga de trabalho, as questões salariais e outras situações que merecem ser investigadas.

As informações das notificações de acidentes de trabalho, segundo escolaridade, apontam para um contingente de $9,7 \%$ dos trabalhadores, com $4^{\mathrm{a}}$ série

Tabela 4 - Distribuição da notificação de acidentes de trabalho em instituições de saúde da Microrregião de Araxá-MG, segundo a escolaridade. Araxá, 2010.

\begin{tabular}{lcc}
\hline Escolaridade & N. & $\mathbf{\%}$ \\
\hline De $1^{\text {a a }} 4^{\text {a }}$ série incompleta & 9 & 9,7 \\
Ensino fundamental completo & 10 & 10,8 \\
Ensino médio incompleto & 2 & 2,2 \\
Ensino médio completo & 36 & 38,7 \\
Ensino superior incompleto & 6 & 6,5 \\
Ensino superior completo & 19 & 20,4 \\
Ignorado & 11 & 11,8 \\
Total & 93 & 100 \\
\hline
\end{tabular}

Fonte: Vigilância Epidemiológica da Secretaria Municipal de Saúde de Araxá-MG.

incompleta. Conforme análise das notificações, esses trabalhadores executam atividades, nas instituições, como serviços gerais e de auxiliar de lavanderia.

$\mathrm{Na}$ medida em que se observa a ocorrência dos acidentes de trabalho entre profissionais com diferentes níveis de qualificação profissional, há estudos que indicam que os acidentes podem estar atrelados ao tipo de atividade que os profissionais executam:

A exposição às cargas de trabalho caracteriza a divisão social e técnica do trabalho, pela maneira como as atividades são divididas e organizadas, pelo grande volume de tarefas, pela repetitividade de procedimentos e isso pode levar a equipe a sentir no próprio corpo o peso da atividade e o desgaste físico e emocional ${ }^{(4: 29)}$.

Neste contexto, vale retomar a importância da Saúde do Trabalhador, que ganhou visibilidade a partir da $1^{\text {a }}$ Conferência Nacional de Saúde dos Trabalhadores, ocorrida em dezembro de 1986. Naquele momento, considerou-se "o trabalho, enquanto organizador da vida social, como espaço de dominação e submissão do trabalhador pelo capital, mas, igualmente, de resistência, de constituição, e do fazer histórico"(16:43). Por estas razões, os trabalhadores deveriam assumir "o papel de atores, de sujeitos capazes de pensar e de se pensarem, produzindo uma experiência própria, no conjunto das representações da sociedade"(16:46).

E, com a criação do Sistema Único de Saúde (SUS), através da Lei Orgânica da Saúde, Lei n. 8.080 de 19 de setembro de 1990, passou a se entender por Saúde do Trabalhador o

conjunto de atividades que se destina, através de ações de vigilância epidemiológica e de vigilância sanitária, à promoção e a proteção da saúde dos trabalhadores, assim como visa à recuperação e a reabilitação da saúde dos trabalhadores submetidos aos riscos e agravos advindos das condições de trabalho ${ }^{(17: 2)}$.

No Brasil, o termo "acidente de trabalho" foi oficializado em 1991. De acordo com a legislação, o acidente de trabalho é aquele que acontece no exercício do trabalho e que traz como consequência uma lesão corporal ou perturbação funcional, com perda ou redução da capacidade para o trabalho, de forma permanente ou temporária, ou até mesmo a morte ${ }^{(18)}$. Por conseguinte, na perspectiva de oferecer uma assistência integral ao trabalhador, o Ministério da Saúde criou, em 2002, através da Portaria n. 1.679, uma Rede Nacional de Atenção Integral à Saúde do Trabalhador (RENAST), tendo como uma das estratégias para a sua estruturação, a organização e implantação de redes de Centros de Referência em Saúde do Trabalhador (CEREST) ${ }^{(5)}$.

A partir de então, a RENAST deve ser constituída por CEREST e por uma rede de serviços médicos e ambulatoriais de média a alta complexidade responsáveis por diagnosticar os acidentes e doenças relacionadas ao trabalho e por registrá-los no Sistema de Informação de Agravos de Notificação (SINANNET). Uma das diretrizes da RENAST é a efetiva implantação de uma Política Nacional de Saúde do Trabalhador (PNST), que responda pela execução de ações curativas, preventivas, de promoção e de reabilitação da Saúde do Trabalhador ${ }^{(5)}$. Portanto, a PNST, vigente a partir de 2004, visa à redução de acidentes e doenças relacionadas ao trabalho.

Ao considerar como marco histórico os avanços das Políticas para a Saúde do Trabalhador, faz-se necessário investir, de forma semelhante, no cumprimento destas legislações pelos estabelecimentos de assistência à saúde, principalmente quando se observa que os riscos ambientais estão se manifestando em números significativos de acidentes de trabalho. Os riscos de ambiente de trabalho podem ser reais e, 
nestas situações, o seu controle é de responsabilidade do empregador ${ }^{(6-7)}$. Entretanto, quando se pressupõe que o trabalhador tem conhecimento sobre as causas que favorecem a ocorrência de acidentes de trabalho, tanto o empregador quanto o trabalhador são corresponsáveis pela redução de acidentes de trabalho.

\section{CONCLUSÃo}

Os dados desta investigação evidenciam a amplitude das informações contidas na Notificação Compulsória de Acidentes de Trabalho da Microrregião de Araxá. E, ainda, oferece subsídios para reafirmar que os acidentes de trabalho podem ser preveníveis, uma vez que já se conhece a maioria dos seus determinantes, as medidas de proteção e a legislação que fortalece a Saúde do Trabalhador.

Estas colocações, por si só, já poderiam ser suficientes para dizer que precisamos colocar em prática as diretrizes da Política Nacional de Saúde do Trabalhador. De que forma? Não temos a receita pronta. $\mathrm{O}$ fato é que todas as estas reflexões somente terão ressonância na medida em que houver uma corresponsabilização entre gestores, diretores, administradores e, principalmente, trabalhadores, em torno de um ideal único, a promoção da "Saúde do Trabalhador". Enfim, espera-se que os resultados desta investigação possam servir de motivação para o efetivo planejamento de ações que contribuam para a redução dos índices de acidentes de trabalho no Estado de Minas Gerais.

\section{REFERÊNCIAS}

1. Waldvogel BC. Acidentes do trabalho: os casos fatais a questão da identificação e da mensuração. Belo Horizonte: Segrac; 2002.

2. International Labour Organization. Safety in numbers: pointers for the global safety culture at work. Geneva: ILO; 2003.

3. Santana VS, Araújo Filho JB, Silva M, Oliveira PRA, Branco A, Nobre L. Mortalidade, anos potenciais de vida perdidos e incidência de acidentes de trabalho na Bahia, Brasil. Cad Saúde Pública. 2007;23(11):2643-52.

4. Sêcco IAO, Robazzi MLCC, Shimizu DS, Rúbio MMS. Acidentes de trabalho típicos envolvendo trabalhadores de hospital universitário da região sul do Brasil: epidemiologia e prevenção. Rev Latino-Am Enfermagem. 2008;16(5):824-31.
5. Ministério da Saúde (BR). III Conferência Nacional de Saúde do Trabalhador: "trabalhar, sim! adoecer, não!": Coletânea de textos /Ministério da Saúde, Ministério do Trabalho e Emprego, Ministério da Previdência e Assistência Social. Brasília; 2005.

6. Marziale MHP, Rodrigues CM. A produção científica sobre os acidentes de trabalho com material pérfuro cortante entre trabalhadores de enfermagem. Rev. Latino-Am. Enfermagem. 2002;10(4): 571-77.

7. Robazzi MLCC, Marziale MHP. A norma regulamentadora n. 32 e suas implicações sobre os trabalhadores de enfermagem. Rev Latino-Am Enfermagem. 2004;12(5):834-6.

8. Pinho DLM, Rodrigues CM, Gomes GP. Perfil dos acidentes de trabalho no Hospital Universitário de Brasília. Rev Bras Enferm. 2007;60(3):291-4.

9. Santana VS, Xavier C, Moura MCP, Oliveira R, Espirito-Santo JR, Araujo G. Gravidade dos acidentes de trabalho atendidos em serviços de emergência. Rev Saúde Pública. 2009;43(5):750-60.

10. Ribeiro EJG, Shimizu HE. Acidentes de trabalho com trabalhadores de enfermagem. Rev Bras Enferm. 2007;60(5):535-40.

11. Miranzi SSC, Gaspar AACS, Iwamoto HH, Miranzi MAS, Dziabas DC. Acidentes de trabalho entre os trabalhadores de uma universidade pública. Rev Bras Saúde Ocup. 2008; 33(118):40-7.

12. Tomasina F, Gómez E, Tchebarne FG. Accidentes laborales en el Hospital de Clínicas. Rev Méd Urug. 2001;17(3):156-60.

13. Valenzuela S, Sanhueza O, Riquelme PN, Fernandez CM, Núnez VR. Salud laboral: situación de los accidentes de trabajo en el equipo de enfermería. Enferm Clin. 2003;13(2): 94-102.

14. Nishide VM, Benatti MCC, Alexandre NMC. Ocorrência de acidente do trabalho em uma unidade de terapia intensiva. Rev Latino-Am Enfermagem. 2004;12(2):204-11.

15. Ribeiro AS, Gabatz RIB, Neves ET, Padoin SMM. Caracterização de acidente com material pérfuro cortante e a percepção da equipe de enfermagem. Cogitare Enferm. 2009; 14(4):660-6.

16. Mendes R, Dias EC. Da medicina do trabalho à saúde do trabalhador. Rev Saúde Pública. 1991;25(5):341-9. 
17. Brasil. Lei n. 8.080, de 19 de setembro de 1990. Dispõe sobre as condições para a promoção, proteção e recuperação da saúde, a organização e o funcionamento dos serviços correspondentes e dá outras providências. Diário Oficial da República Federativa do Brasil, Brasília: 1990 [Internet] [acesso em 02 fev 2010]. Disponível: http://tiny.cc/0utlq

18. Brasil. Lei n. 8.213, de 24 de julho de 1991. Dispõe sobre os Planos de Benefícios da Providência Social e dá outras providências. Diário Oficial da República Federativa do Brasil [Internet]. Brasília: Presidência da República, 1991. [acesso em 02 fev 2010]. Disponível: http://tiny.cc/u4zgc 